\author{
Martijn Miedema \\ Frans H. de Jongh \\ Inez Frerichs \\ Mariëtte B. van Veenendaal \\ Anton H. van Kaam
}

\section{Regional respiratory time constants during lung recruitment in high-frequency oscillatory ventilated preterm infants}

Received: 9 May 2011

Accepted: 12 October 2011

Published online: 29 November 2011

(C) The Author(s) 2011. This article is published with open access at Springerlink.com
M. Miedema ( $\bullet$ - F. H. de Jongh . M. B. van Veenendaal - A. H. van Kaam Department of Neonatology, Emma Children's Hospital,

Academic Medical Center, P.O. Box 22660, Amsterdam 1100 DD, The Netherlands e-mail: m.miedema@amc.uva.nl Tel.: +31-20-5669111

Fax: +31-20-6965099

I. Frerichs

Department of Anesthesiology and Intensive Care Medicine, University Medical Center, Schleswig-Holstein campus, Kiel, Germany
Abstract Purpose: To assess the regional respiratory time constants of lung volume changes during stepwise lung recruitment before and after surfactant treatment in high-frequency oscillatory ventilated preterm infants. Methods: A stepwise oxygenation-guided recruitment procedure was performed before and after surfactant treatment in highfrequency oscillatory ventilated preterm infants. Electrical impedance tomography was used to continuously record changes in lung volume during the recruitment maneuver. Time constants were determined for all incremental and decremental pressure steps, using one-phase exponential decay curve fitting. Data were analyzed for the whole cross section of the chest and the ventral and dorsal lung regions separately. Results: Before surfactant treatment, the time constants of the incremental pressure steps were significantly longer (median $27.3 \mathrm{~s}$ ) than those in the decremental steps (16.1 s). Regional analysis showed only small differences between the ventral and dorsal lung regions. Following surfactant treatment, the time constants during decremental pressure steps almost tripled to 44.3 s. Furthermore, the time constants became significantly $(p<0.01)$ longer in the dorsal (61.2 s) than into the ventral (40.3 s) lung region. Conclusions: Lung volume stabilization during stepwise oxygenation-guided lung recruitment in high-frequency oscillatory ventilated preterm infants with respiratory distress syndrome is usually completed within $5 \mathrm{~min}$ and is dependent on the position of ventilation on the pressure volume curve, the surfactant status, and the region of interest of the lung.

Keywords Premature infant . High-frequency oscillatory ventilation - Time constants . Electrical impedance tomography . Surfactant

\section{Introduction}

High-frequency oscillatory ventilation (HFOV) is often used as a lung protective ventilation mode in preterm infants [1]. However, animal studies have clearly shown that HFOV will only attenuate ventilation-induced lung injury if combined with an optimal lung volume or open lung ventilation strategy $[2,3]$. Such an open lung strategy aims at recruiting and stabilizing collapsed alveoli with the lowest possible airway pressure thereby placing ventilation on the more compliant deflation limb of the pressure-volume relationship of the lung [4].

In daily clinical practice the recruitment procedure during open lung HFOV is usually guided by changes in oxygenation in response to small incremental and decremental pressure steps [5, 6]. It is, however, unknown how much time it takes for lung volume to stabilize after each pressure step in preterm infants with respiratory distress 
syndrome (RDS). Furthermore, it is unclear if this stabilization time is similar in the different lung regions or if it changes with the position of ventilation on the pressure-volume curve or the surfactant status of the lung. This information is essential to determine the optimal interval between pressure steps. Setting this interval too short may result in the use of excessive pressures resulting in possible (regional) overdistension, whereas taking too much time between the steps will make the recruitment procedure too time-consuming.

Two studies assessed the effect of mean airway pressure on lung volume in preterm infants on HFOV, reporting stabilization times between 2 and $25 \min [7,8]$. However, changes in lung volume were not continuously measured, which would have been the optimal approach to assess the exact time for (regional) lung volume to stabilize.

Electrical impedance tomography (EIT) is a noninvasive bedside tool capable of continuously measuring (regional) changes in lung impedance, which are highly correlated with changes in gas volume [9]. In the present study we used EIT to monitor and determine the (regional) time constants during a recruitment maneuver before and after surfactant instillation in high-frequency oscillatory ventilated premature infants with RDS. We hypothesize that the time constant is dependent on the position of ventilation on the pressure-volume curve, the surfactant status of the lung, and the analyzed region of interest within the lungs.

\section{Materials and methods}

Patients

The study was performed in the neonatal intensive care unit of the Emma Children's Hospital, Academic Medical Center (Amsterdam, the Netherlands), where preterm infants ( $<37$ weeks) with a suspected diagnosis of RDS and failing nasal continuous positive airway pressure are treated with open lung HFOV. Infants were included in the study if HFOV was started within $72 \mathrm{~h}$ after birth and written informed consent was obtained from both parents. Exclusion criteria were congenital anomalies, severe circulatory shock, or persistent pulmonary hypertension of the newborn. All patients were ventilated in supine position and were not sedated or paralyzed. The study was approved by the institutional review board.

\section{Ventilation protocol}

A protocolized and individualized open lung ventilation strategy was performed in all patients with HFOV, which was delivered by a Sensormedics 3100A oscillator (Carefusion, Hoechberg, Germany). The strategy aimed at recruiting and stabilizing collapsed alveoli, using oxygenation as a proxy for lung volume [5]. Starting at a continuous distending pressure $\left(\mathrm{CDP}_{\mathrm{st}}\right)$ of $6-8 \mathrm{cmH}_{2} \mathrm{O}$ the pressure was stepwise increased by $1-2 \mathrm{cmH}_{2} \mathrm{O}$ until oxygenation no longer improved or the fractional inspired oxygen $\left(\mathrm{FIO}_{2}\right)$ was no greater than 0.25 (opening pressure, $\left.\mathrm{CDP}_{\mathrm{o}}\right)$. Next, the CDP was stepwise $\left(1-2 \mathrm{cmH}_{2} \mathrm{O}\right)$ decreased until $\mathrm{SpO}_{2}$ deteriorated, indicating alveolar/ saccular collapse (closing pressure, $\mathrm{CDP}_{\mathrm{c}}$ ). The lung was then once again opened $\left(\mathrm{CDP}_{\mathrm{O}}\right)$ and pressure set $2 \mathrm{cmH}_{2} \mathrm{O}$ above the $\mathrm{CDP}_{\mathrm{c}}$ (optimal CDP, $\mathrm{CDP}_{\mathrm{opt}}$ ). The time interval between pressure steps was dependent on the change in oxygenation. If oxygenation did not change following a pressure step or stabilized after an $\mathrm{FIO}_{2}$ adjustment, the clinician waited at least 2 min before taking the next pressure step. The pressure amplitude was set in such a way that chest oscillations were visible with a frequency of $10 \mathrm{~Hz}$ and an inspiration time of 33\%. After checking the endotracheal tube position by chest radiography, each infant received surfactant and the $\mathrm{CDP}_{\mathrm{c}}, \mathrm{CDP}_{\mathrm{o}}$, and $\mathrm{CDP}_{\text {opt }}$ were once more determined by the same procedure as described above, but now with a minimum time interval between pressure steps of $5 \mathrm{~min}$. The procedure started with decremental pressure steps unless the $\mathrm{FIO}_{2}$ increased to greater than 0.25 after surfactant treatment, in which case CDP was increased in search of the new $\mathrm{CDP}_{\mathrm{o}}$. If the CDP could be reduced to $8 \mathrm{cmH}_{2} \mathrm{O}$ without compromising oxygenation, the closing procedure was stopped and the corresponding CDP was designated as the $\mathrm{CDP}_{\text {opt }}$.

\section{EIT measurements}

Before intubation 16 hand-trimmed ECG electrodes (BlueSensor, BRS-50-K, Ambu, Inc., Linthicum) were placed equidistantly on the thorax circumference of the newborn just above the nipple line and connected to the Goe-MF II EIT system (Carefusion, Hoechberg, Germany). Repetitive electrical currents $\left(5 \mathrm{~mA}_{\mathrm{rms}}, 100 \mathrm{kHz}\right)$ were injected in rotation (scan rate $44 \mathrm{~Hz}$ ) through adjacent electrode pairs and voltage changes were measured by all other passive electrodes pairs. A backprojection image reconstruction algorithm generated a $32 \times 32$ matrix of local relative impedance changes $(\Delta \mathrm{Z}) \mathrm{com}-$ pared to a reference state. Continuous online recording of impedance changes and airway pressure was started as soon as the patient was connected to the oscillator, using Veit software (Carefusion, Hoechberg, Germany). EIT data were analyzed off-line using AUSPEX version 1.6 (VUMC, Amsterdam, the Netherlands). The clinician performing the recruitment procedure was blinded for the EIT tracing. 
Off-line analyses

Time constants were calculated for all incremental and decremental pressure steps during the pre- and postsurfactant recruitment procedures. First, the relative impedance change after each pressure step was calculated, using a stable 10 -s recording period just before the pressure step as a reference. Next, all individual data points of relative $\Delta \mathrm{Z}$ were plotted against time, using the integrated airway pressure signal to determine the start of each pressure step (time $=0 \mathrm{~s}$ ). A one-phase exponential decay curve fitting $\left(y=y_{0} \times \mathrm{e}^{-(t / \tau)}\right)$ using no constraints was applied to calculate the time constant for each impedance-time curve (Fig. 1). To test the accuracy of the model we averaged the raw impedance data over 0.5 -s consecutive periods in 100 randomly selected incremental and decremental pressure steps. These newly derived points were used to fit a one-phase exponential decay curve and the time constant including the goodness of fit $\left(R^{2}\right)$ was calculated.

In case of intermittent spontaneous breathing, the individual breaths were removed from the tracing to improve the accuracy of curve fitting (Fig. 1). During some pressure steps movement artifacts or continuous spontaneous breathing prevented accurate curve fitting and these steps were excluded from the analyses. Lung volume was considered stable after a pressure step if the impedance tracing showed no visual change in lung volume and curve fitting was not possible because of a lack in exponential behavior.

In addition to the time constants determined in the whole chest cross section, we also calculated the time constants in the ventral and dorsal half of the matrix separately. The effects of lung volume history (inflation vs deflation), surfactant treatment (before vs after), spontaneous breathing (none vs present), and region of interest (dorsal vs ventral) on time constant were assessed by comparative analysis.

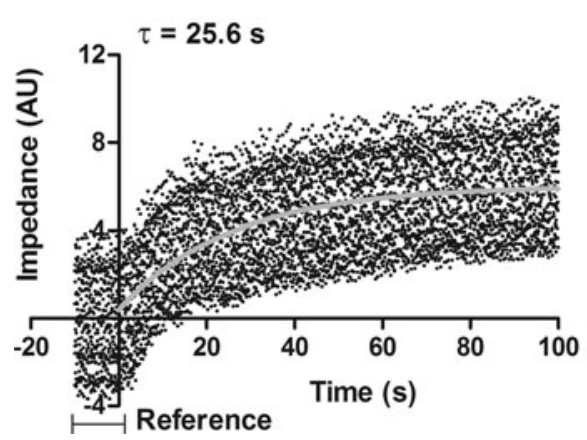

Fig. 1 Representative example of an impedance recording without (left panel) and with (right panel) spontaneous breathing following an incremental pressure step of $2 \mathrm{cmH}_{2} \mathrm{O}$. The one-phase exponential decay fitting curve is indicated as a dark gray line. Note the
Statistical analysis

For statistical analysis we used GraphPad Prism 5.0 (Graphpad Software Inc., San Diego, USA) and SPSS version 16.0 (SPSS Inc., Chicago, USA). Depending on their distribution, data were expressed as mean \pm standard deviation (SD) or as median with interquartile ranges (IQR). For comparative analyses the Mann-Whitney or Wilcoxon signed rank test were used for skewed data and the Student $t$ test for normally distributed data. A $p$ value less than 0.05 was considered statistically significant.

\section{Results}

Twenty-two patients completed the study protocol without complications (Table 1). The mean $\mathrm{CDP}_{\mathrm{st}}$ was $8.7 \pm$ $1.8 \mathrm{cmH}_{2} \mathrm{O}$ with a corresponding $\mathrm{FIO}_{2}$ of $0.82 \pm 0.25$. The lungs were recruited with a $\mathrm{CDP}_{\mathrm{o}}$ of $20.1 \pm 3.2 \mathrm{cmH}_{2} \mathrm{O}$, resulting in a significant drop in $\mathrm{FIO}_{2}$ to $0.26 \pm 0.06$ $(p<0.01)$. Oxygenation deteriorated at a mean pressure of $11.3 \pm 2.2 \mathrm{cmH}_{2} \mathrm{O}\left(\mathrm{CDP}_{\mathrm{c}}\right)$ resulting in a $\mathrm{CDP}_{\mathrm{opt}}$ of $13.2 \pm 2.2 \mathrm{cmH}_{2} \mathrm{O}$ with a mean $\mathrm{FIO}_{2}$ of $0.26 \pm 0.06$. Following surfactant treatment airway pressures could be weaned to a mean $\mathrm{CDP}_{\mathrm{opt}}$ of $8.6 \pm 1.1 \mathrm{cmH}_{2} \mathrm{O}$ with a mean $\mathrm{FIO}_{2}$ of $0.23 \pm 0.03$. In the majority of patients the

Table 1 Patient characteristics

\begin{tabular}{ll}
\hline Characteristics & Value \\
\hline Gestational age (days) & $28.3 \pm 2.5$ \\
Birth weight (g) & $1,167 \pm 464$ \\
Antenatal steroids, $n(\%)$ & $19(86)$ \\
Five minutes Apgar score* & $8(6.3-9)$ \\
Age at start HFOV $(\mathrm{h})^{*}$ & $4(2-7)$ \\
\hline
\end{tabular}

Data are presented as mean $\pm \mathrm{SD}$ of 22 patients or median (IQR) when stated differently $(*)$

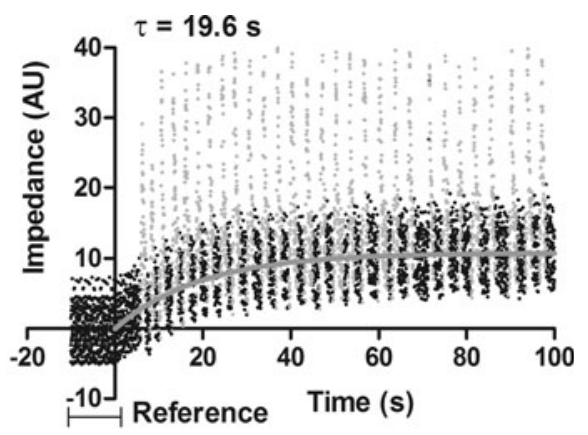

deleted spontaneous breaths (light gray dots) in the right panel. 95\% confidence interval of described time constant: left panel, $23.16-28.60 \mathrm{~s}$; right panel, $17.58-22.03 \mathrm{~s}$. $A U$ arbitrary units, $\tau$ time constant 
Table 2 Time constants based on the impedance changes analyzed in the whole chest cross section and regions of interest (ventral/dorsal) during incremental and decremental pressure steps before and after surfactant treatment

\begin{tabular}{|c|c|c|c|}
\hline & $\begin{array}{l}\text { Global } \tau \\
\text { (s) }\end{array}$ & $\begin{array}{l}\text { Ventral } \tau \\
\text { (s) }\end{array}$ & $\begin{array}{l}\text { Dorsal } \tau \\
\text { (s) }\end{array}$ \\
\hline Inflation limb before surfactant $(n=95)$ & $27.3(12.5-53.9)$ & $28.5(12.8-62.7)$ & $23.0(8.9-52.7)^{\mathrm{a}}$ \\
\hline Deflation limb before surfactant $(n=89)$ & $16.1(7.8-30.6)^{\mathrm{b}}$ & $16.3(7.3-29.2)^{\mathrm{b}}$ & $18.7(8.8-44.5)^{\mathrm{b}}$ \\
\hline Deflation limb after surfactant $(n=25)^{\mathrm{d}^{\prime}}$ & $44.3(30.1-70.8)^{\mathrm{c}}$ & $40.3(22.5-64.5)^{\mathrm{c}}$ & $61.2(30.5-83.5)^{\mathrm{a}, \mathrm{c}}$ \\
\hline $\mathrm{CDP}_{\mathrm{c}}-\mathrm{CDP}_{\mathrm{o}}(n=13)$ & $12.6(11.4-22.7)^{\mathrm{b}}$ & $12.4(10.1-23.0)^{b}$ & $13.0(11.1-20.6)^{b}$ \\
\hline
\end{tabular}

$C D P_{c}$ closing pressure, $C D P_{o}$ openings pressure, $\tau$ time constant

${ }^{a}$ Significant change compared to the ventral $\tau, p<0.01$

b Significant change compared to the inflation limb before surfactant $\tau, p<0.01$

lung did not close at a CDP of $8 \mathrm{cmH}_{2} \mathrm{O}$ and for this reason the $\mathrm{CDP}_{\mathrm{o}}$ after surfactant treatment was not determined in these infants. The median time spent at each pressure step was $180 \mathrm{~s}$ (IQR 140-210 s) presurfactant and $265 \mathrm{~s}$ (IQR 238-320 s) postsurfactant.

Ninety-five $(83 \%)$ of the 115 incremental and 87 (96\%) of the 93 decremental presurfactant pressure steps could be analyzed. After surfactant treatment most decremental pressure steps did not result in a decrease in lung volume, leaving only $25(40 \%)$ of the 62 steps for time constant analysis. Nine $(41 \%)$ registrations of the 22 pressure increases from $\mathrm{CDP}_{\mathrm{c}}$ to $\mathrm{CDP}_{\mathrm{o}}$ had to be excluded from analysis, mainly due to excessive spontaneous breathing.

As shown in Table 2, the median time constant during incremental pressure steps before surfactant treatment was $27.3 \mathrm{~s}$ (IQR 12.5-53.9). During decremental steps the time constant was significantly shorter (16.1 s (IQR 7.8-30.6), $p<0.01$ ). Taking a relatively large pressure step from $\mathrm{CDP}_{\mathrm{c}}$ to $\mathrm{CDP}_{\mathrm{o}}\left(8.8 \pm 3.0 \mathrm{cmH}_{2} \mathrm{O}\right.$ increase $)$ at the end of the presurfactant recruitment procedure resulted in a median time constant of $12.6 \mathrm{~s}$ (IQR 11.4-22.7) which was significantly shorter than that of the smaller incremental pressure steps (Table 2). Regional analyses showed significantly shorter time constants in the dorsal lung regions during the incremental, but not the decremental, pressure steps.

After surfactant instillation the time constants of the decremental pressure steps almost tripled to $44.3 \mathrm{~s}$ (IQR 30.1-70.8). In contrast to the surfactant deficient lung, the postsurfactant time constants of the decremental pressure steps were significantly longer in the dorsal compared with the ventral lung region (Table 2).

Subgroup analysis of pressure steps with and without spontaneous breathing showed no significant difference in time constants between the groups (data not shown).

The median time constants calculated from the averaged impedance data in the randomly selected pressure steps was similar to the time constants calculated by modeling the raw impedance data. The mean $R^{2}$ values c Significant change compared to the deflation limb before surfactant $\tau, p<0.01$

${ }^{\mathrm{d}}$ Of note, in the remaining 38 decremental pressure steps no change in lung volume was observed

\section{Discussion}

The present study provides, for the first time, the time constants of the lung during stepwise oxygenation-guided lung recruitment in high-frequency ventilated preterm infants with RDS. It shows that the time constants are dependent on the position of ventilation on the pressurevolume curve, the surfactant status, and the region of interest of the lung.

The time constant, which is the product of compliance and resistance, is defined as the time necessary to complete $63 \%$ of the total change in lung volume following a tidal breath or in response to a pressure step. On the basis of this definition, it will take approximately three time constants to complete $95 \%$ of the lung volume change. Translating this physiological principle to our study, results in a median time of $82 \mathrm{~s}$ for lung volume to stabilize after an incremental pressure step in the surfactant deficient lung. Interestingly, this stabilization was significantly shorter (48 s) when moving down the deflation limb of the pressure-volume curve via decremental pressure steps. It is important to realize that lung volume changes during inflation are caused by a combination of alveolar recruitment and distension, whereas during deflation the changes are mainly the result of less distension. Because previous experimental studies have shown that alveolar recruitment is a relatively slow process compared with alveolar distension this may, in part, explain the longer time constants during inflation [10]. The fact that we found time constants during the large incremental pressure steps from $\mathrm{CDP}_{\mathrm{c}}$ to $\mathrm{CDP}_{\mathrm{o}}$ similar to the deflation steps seems to support this explanation because the contribution of alveolar recruitment in this pressure step is also relatively small. 
In line with previous studies, we used one-phase exponential decay curve fitting to calculate the time constant $[8,11]$. Although there are some indications that two-phase exponential decay curve fitting may result in more accurate modeling in adults performing a forced exhalation, we could not show a clear difference in stabilization time when analyzing a small sample of random pressure steps with both one- and two-phase exponential decay curve fitting in these high-frequency ventilated preterm infants with $\operatorname{RDS}[10,12]$. Furthermore, we found an excellent goodness of fit when modeling a onephase exponential decay curve through the averaged impedance levels over 0.5 -s periods in 100 randomly selected pressure steps, supporting the robustness of the used model.

We also assessed the presurfactant time constants in the ventral and dorsal lung region because studies in animals and adults with acute lung injury have shown that lung disease and the response to lung recruitment are often heterogeneous in nature, following a gravity-dependent pattern [13]. In contrast to these studies, the ventral and dorsal time constants were relatively similar in this cohort of preterm infants with RDS. Although this finding seems to suggest that RDS is a relatively homogenous disease, definite conclusions cannot be drawn as we only explored two regions of interest in the gravitational axis and less dramatic gravity-dependent differences were possibly not detected due to the small size of the infants. Further studies will have to address this issue.

Following surfactant administration, the time constants during decremental pressure steps almost tripled, resulting in a median stabilization time of approximately $2 \mathrm{~min}$. This increase is probably best explained by the improvement in lung compliance after surfactant treatment. It was also interesting to observe that $60 \%$ of the decremental pressure steps did not result in a change in lung volume, thus substantiating previous findings that surfactant stabilizes the deflation limb of the pressure volume relationship [14]. Interestingly, regional analysis showed that the decremental time constants after surfactant are significantly longer in the dorsal region compared with the ventral regions. This finding strongly suggests that the distribution of exogenous surfactant favors the dorsal (gravity-dependent) lung regions, as also suggested by previous animal data [15].

To date, the stabilization time in HFOV newborn infants in response to changes in mean airway pressure has only been assessed in two studies [7, 8]. In contrast to our findings, Thome and colleagues found much longer stabilization times (median time $9 \mathrm{~min}$ ) with a large variation (2-25 $\mathrm{min})$ in preterm infants with RDS. There may be several reasons for this discrepancy. First, lung volume changes were only intermittently measured using a sulfur hexafluoride washout technique, which is probably less accurate then the continuous monitoring with
EIT used in our study. Second, the washout method required a switch from HFOV to conventional mechanical ventilation using peak inspiratory pressures of $20-22 \mathrm{cmH}_{2} \mathrm{O}$, which undoubtedly affected the lung volume status and the determined time constants. Finally, the median age at the time of lung volume measurements was 4 days, in contrast to the $4 \mathrm{~h}$ in our study. At that age, RDS may have evolved into a more heterogeneous lung disease, and affected both the stabilization time and the variance [16]. Tingay and colleagues reported time-related changes in lung volume in, mostly, term infants using respiratory induction plethysmography [8]. They showed similar stabilization times, supporting the findings of this study.

This study has several limitations that need to be addressed. First, EIT only provides information on a transverse "slice" of the lung. Considering the fact that RDS is a relatively homogeneous lung disease, it is very likely that the EIT findings as described in this study are representative for the entire lung. Second, oxygenation was used to determine the time interval between pressure steps. Oxygenation will remain stable if the change in lung volume is caused by lung distension rather than recruitment. In theory, this may have resulted in time intervals that are too short to allow the impedance signal to stabilize, especially during lung deflation. However, the fact that $96 \%$ of the deflation pressure steps could be analyzed strongly suggests that the minimum time interval of 2 min between pressure steps was sufficient to allow for reliable modeling. Third, the findings are found in a selected patient category and the time constants in older infants or in infants with a more heterogeneous pulmonary disease can be different. Fourth, a fixed oscillation frequency and inspiration to expiration ratio were used and the results may be different when using other ventilatory settings. Finally, all infants were highfrequency oscillatory ventilated and future studies will have to investigate if our findings are also applicable to lung recruitment during conventional positive pressure ventilation.

Despite these limitations this study has important implications for clinicians performing bedside oxygenation-guided lung recruitment in high-frequency oscillatory ventilated surfactant-deficient preterm infants. Our study suggests that clinicians should wait at least 3 min before taking a new incremental pressure step and 2 min before taking a decremental step. Following surfactant treatment, deflation steps should be taken every $5 \mathrm{~min}$. These suggested time intervals should be extended if oxygenation has not yet stabilized within the proposed time frames. Finally, our study shows that EIT can provide valuable bedside information on changes in lung volume during lung recruitment which may be especially beneficial in those circumstances where oxygenation is not a reliable tool to assess changes in lung volume. 


\section{Conclusions}

This study shows that changes in lung volume during stepwise oxygenation-guided lung recruitment in highfrequency oscillatory ventilated preterm infants with RDS are usually completed within $5 \mathrm{~min}$ and that this stabilization time is dependent on the position of ventilation on the pressure-volume curve of the respiratory system, the surfactant status of the lung, and the region of interest.
Acknowledgments This work was financially supported by Chiesi Pharmaceutical. The EIT device was kindly provided by Carefusion.

Open Access This article is distributed under the terms of the Creative Commons Attribution Noncommercial License which permits any noncommercial use, distribution, and reproduction in any medium, provided the original author(s) and source are credited.

\section{References}

1. van Kaam AH, Rimensberger PC, Borensztajn D, De Jaegere AP (2010) Ventilation practices in the neonatal intensive care unit: a cross-sectional study. J Pediatr 157:767-771

2. McCulloch PR, Forkert PG, Froese AB (1988) Lung volume maintenance prevents lung injury during high frequency oscillatory ventilation in surfactant-deficient rabbits. Am Rev Respir Dis 137:1185-1192

3. van Kaam AH, de Jaegere A, Haitsma JJ, Van Aalderen WM, Kok JH, Lachmann B (2003) Positive pressure ventilation with the open lung concept optimizes gas exchange and reduces ventilator-induced lung injury in newborn piglets. Pediatr Res 53:245-253

4. Rimensberger PC, Cox PN, Frndova H, Bryan AC (1999) The open lung during small tidal volume ventilation: concepts of recruitment and "optimal" positive end-expiratory pressure. Crit Care Med 27:1946-1952

5. De Jaegere A, van Veenendaal MB, Michiels A, van Kaam AH (2006) Lung recruitment using oxygenation during open lung high-frequency ventilation in preterm infants. Am J Respir Crit Care Med 174:639-645

6. Johnson AH, Peacock JL, Greenough A, Marlow N, Limb ES, Marston L, Calvert SA (2002) High-frequency oscillatory ventilation for the prevention of chronic lung disease of prematurity. N Engl J Med 347:633-642
7. Thome U, Topfer A, Schaller P, Pohlandt F (1998) Effects of mean airway pressure on lung volume during high-frequency oscillatory ventilation of preterm infants. Am J Respir Crit Care Med 157:1213-1218

8. Tingay D, Mills JF, Morley CJ, Pellicano A, Dargaville PA (2005) Time to stabilise lung volume after changing mean airway pressure during HFOV. Pediatric American Society Abstract 57:2044

9. Victorino JA, Borges JB, Okamoto VN, Matos GF, Tucci MR, Caramez MP, Tanaka H, Sipmann FS, Santos DC, Barbas CS, Carvalho CR, Amato MB (2004) Imbalances in regional lung ventilation: a validation study on electrical impedance tomography. Am J Respir Crit Care Med 169:791-800

10. Markstaller K, Eberle B, Kauczor HU, Scholz A, Bink A, Thelen M, Heinrichs W, Weiler N (2001) Temporal dynamics of lung aeration determined by dynamic CT in a porcine model of ARDS. Br J Anaesth 87:459-468

11. Bates JH, Irvin CG (2002) Time dependence of recruitment and derecruitment in the lung: a theoretical model. J Appl Physiol 93:705-713
12. Steltner H, Vogel M, Sorichter S, Matthys H, Guttmann J, Timmer J (2001) Analysis of forced expired volume signals using multi-exponential functions. Med Biol Eng Comput 39:190-194

13. Pelosi P, D'Andrea L, Vitale G, Pesenti A, Gattinoni L (1994) Vertical gradient of regional lung inflation in adult respiratory distress syndrome. Am J Respir Crit Care Med 149:8-13

14. Miedema M, de Jongh FH, Frerichs I, van Veenendaal MB, van Kaam AH (2011) Changes in lung volume and ventilation during surfactant treatment in ventilated preterm infants. Am J Respir Crit Care Med 184:100-105

15. Broadbent R, Fok TF, Dolovich M, Watts J, Coates G, Bowen B, Kirpalani $\mathrm{H}$ (1995) Chest position and pulmonary deposition of surfactant in surfactant depleted rabbits. Arch Dis Child Fetal Neonatal Ed 72:F84-F89

16. Adams EW, Counsell SJ, Hajnal JV, Cox PN, Kennea NL, Thornton AS, Bryan AC, Edwards AD (2002) Magnetic resonance imaging of lung water content and distribution in term and preterm infants. Am J Respir Crit Care Med 166:397-402 